\title{
Minireview
}

\section{Primary thromboprophylaxis for cancer patients with central venous catheters - a reappraisal of the evidence}

\author{
MS Cunningham ',2, B White', D Hollywood ${ }^{2}$ and J O'Donnell ${ }^{*, 1}$ \\ 'Department of Haematology, Institute of Molecular Medicine, St. James's Hospital and Trinity College, Dublin, Ireland; ${ }^{2}$ Academic Unit of Clinical and \\ Molecular Oncology, Institute of Molecular Medicine, St. James's Hospital and Trinity College, Dublin, Ireland
}

\begin{abstract}
Venous thromboembolism (VTE) is responsible for an estimated 25000 deaths per annum in UK hospital practice. It is well established that many of these deaths could be prevented through the use of appropriate thromboprophylaxis. This issue is of particular relevance in oncology practice, where the risks of VTE and bleeding are both significantly higher than those observed in general medical patients. Cancer patients with in-dwelling central venous catheters (CVCs) are at particularly high risk of developing thrombotic complications. However, the literature has produced conflicting conclusions regarding the efficacy of using routine primary thromboprophylaxis in these patients. Indeed such is the level of confusion around this topic, that the most recent version of the American College of Chest Physicians (ACCP) guidelines published in 2004 actually reversed their previous recommendation (published in 200I). Nevertheless, minidose warfarin continues to be routinely used in many oncology centres in the UK. In this article, we have performed a systematic review of the published literature regarding the efficacy and the risks, associated with using thromboprophylaxis (either minidose warfarin or low-dose LMWH) in cancer patients with CVC. On the basis of this evidence, we conclude that there is no proven role for using such thromboprophylaxis. However, asymptomatic CVC-related venous thrombosis remains common, and further more highly powered studies of better design are needed in order to define whether specific subgroups of cancer patients might benefit from receiving thromboprophylaxis.

British Journal of Cancer (2006) 94, I89-194. doi:I0.1038/sj.bjc.66029 I7 www.bjcancer.com

Published online 10 January 2006

(c) 2006 Cancer Research UK
\end{abstract}

Keywords: central venous catheter; malignancy; thrombosis; antithrombotic prophylaxis

In the developed world, venous thromboembolism (VTE) develops in approximately one in 1000 people each year (Oger, 2000). It typically presents as a deep vein thrombosis (DVT) of the calf, which may extend proximally into the veins of the thigh. These proximal DVT can then give rise to pulmonary embolism (PE) (Kearon, 2003). Studies have demonstrated that PE are directly responsible for approximately $10 \%$ of all hospital in-patient deaths, and that they contribute to a further $15 \%$ (Geerts et al, 2004). Consequently, over 25000 people are estimated to die from VTE each year in England alone, and clinical management of acute VTE costs the UK in excess of $£ 600$ million per annum.

It is well recognised that patients with cancer constitute a particularly high-risk group for both arterial and VTE. Compared to age and sex-matched controls, the relative risk of VTE is increased approximately five-fold in patients with cancer (Heit et al, 2000). Clinically symptomatic DVT have been reported in up to $15 \%$ of patients with cancer (Bick, 1978). However postmortem studies have demonstrated asymptomatic VTE in as many as $50 \%$ (Ambrus et al, 1975). Multiple mechanisms have been implicated in explaining the increased incidence of VTE associated with cancer (Piccioli et al, 1996). Moreover, it is well established that specific therapeutic interventions (including surgery, chemotherapy

*Correspondence: Dr J O’Donnell; E-mail: jodonnell@stjames.ie Received 30 August 2005; revised 28 November 2005; accepted 28 November 2005; published online 10 January 2006 or hormone-based treatment) can further increase the absolute risk of VTE (Lee, 2005).

Central venous catheters (CVCs) were initially developed by Broviac et al in 1973, (Broviac et al, 1973) and then subsequently modified by Hickman et al (1979). They are now widely used in cancer patients who require intensive chemotherapy and/or stem cell transplantation. These venous access devices are typically in the form of either an external catheter (e.g. Hickman or Groshong line), or an implanted subcutaneous port (e.g. Port-a-Cath). Although central venous access has revolutionised the clinical management of cancer patients, there is strong evidence to suggest that both catheters and ports are associated with a significant increase in the rate of VTE. The aetiology of CVC-related thrombosis is likely to be multifactorial in origin. Insertion of CVCs is associated with traumatic damage to the vessel wall, and further damage to the endothelial cell lining of the vessel wall may occur depending upon the final position of the line tip (Eastridge and Lefor, 1995). In addition, total parenteral nutrition, chemotherapy and other drugs infused through the CVC may exacerbate any local areas of vessel wall damage (Baglin and Boughton, 1986). Cancer patients with constitutional thrombophilias (notably antithrombin deficiency) appear to be at an increased risk of CVC-related thrombosis, (De Cicco et al, 1995; Tesselaar et $a l, 2004)$ as do those with elevated homocysteine levels, but not those with the factor V Leiden or prothrombin 20210A gene mutations (De Cicco et al, 1995; Tesselaar et al, 2004). Ovarian carcinoma has also been associated with a higher incidence of 
CVC-related venous thrombosis compared to other tumour types (Tesselaar et al, 2004).

The high rate of VTE associated with CVC in cancer patients has led to the suggestion that all such patients should receive primary thromboprophylaxis (in the form of either heparin or warfarin). Indeed the practise of using thromboprophylaxis for cancer patients with CVC is now considered routine practise in many oncology centres across the UK. However, it is well established that heparin or warfarin use in cancer patients is associated with an increased risk of bleeding. Consequently the appropriate role of primary thromboprophylaxis in cancer patients with CVCs represents a controversial area. In order to establish whether the available evidence supports current practise, we have performed a systematic review of the published literature on the efficacy and the risks associated with using thromboprophylaxis (either minidose warfarin, or LMWH), in cancer patients with indwelling CVC.

\section{METHODS}

\section{Search strategy}

Data for this review was identified by searching the electronic databases MEDLINE, EMBASE and the Cochrane Library (encompassing period January 1966 until November 2005) by two independent reviewers (MC, JOD). The search terms were 'catheterisation, central venous', 'thrombosis', 'oncology', 'neoplasms', 'adult', 'anticoagulation therapy' and 'haematological' as Medical Subject Heading (MeSH) terms and text words. In addition, the bibliographies of all retrieved articles were also manually searched for additional relevant articles. Only full papers published in English between 1980 and 2005 were considered.

\section{Selection criteria}

Studies were included in the review if they met the following criteria:

- Prospective design.

- Study population consisted of adult (more then 14 years) cancer patients, receiving a CVC - defined as either implantable port or external catheter.

- Site of catheter insertion defined.
- Some or all of the patients received either heparin or warfarin thromboprophylaxis at clearly specified dose.

For most articles, selection criteria were apparent. For articles in which criteria were unclear, the decision for selection was made by consensus among all the authors.

\section{Data extraction and synthesis}

Each study fulfilling the inclusion criteria was reviewed independently, by two or more of the authors. All data were extracted according to a predetermined standard checklist. Disagreements were resolved by consensus among the authors. The methodologic quality of each study was critically examined. Clinical outcomes of interest included incidence of asymptomatic and/or symptomatic DVT, PE, and overall mortality. In view of the nature of the data retrieved, quantifiable analysis (met-analysis) was not performed as part of this study.

\section{RESULTS}

Using the specified selection criteria, a total of nine prospective studies of thromboprophylaxis use in adult cancer patients with CVC were identified (Table 1) (Bozzetti et al, 1983; Bern et al, 1990; Monreal et al, 1996; Nightingale et al, 1997; Boraks et al, 1998; Heaton et al, 2002; Mismetti et al, 2003; Couban et al, 2005; Verso et al, 2005). Of these studies, one investigated unfractionated heparin thromboprophylaxis, (Bozzetti et al, 1983) while another three studied the efficacy of different low molecular weight heparin preparations (dalteparin, nadroparin and enoxaparin, respectively) (Monreal et al, 1996; Mismetti et al, 2003; Verso et al, 2005). Use of minidose warfarin (1 mg daily) was studied in six independent trials, incorporating 1463 patients (Bern et al, 1990; Nightingale et al, 1997; Boraks et al, 1998; Heaton et al, 2002; Mismetti et al, 2003; Couban et al, 2005).

\section{Incidence of catheter-related thrombosis in cancer patients}

In the general population, upper limb DVT is uncommon, accounting for only approximately $2 \%$ of all episodes of DVT (Marie et al, 1998; Marinella et al, 2000). Long-term indwelling CVCs appear to be the most common predisposing factor for upper limb DVT, and have been implicated in between 22 and $72 \%$

Table I Description of the prospective studies on thromboprophylaxis for cancer patients with CVC included in this review

\begin{tabular}{|c|c|c|c|c|c|c|c|c|}
\hline Study & $n$ & Catheter & Location & Intervention & Duration & Test & Objective VTE & Symptomatic VTE \\
\hline $\begin{array}{l}\text { Monreal et al (1996) } \\
\text { (open randomised study) }\end{array}$ & 32 & Port & Subclavian & $\begin{array}{l}\text { Fragmin } 2500 \mathrm{IU} \text { s.c. } \\
\text { once daily }\end{array}$ & 90 days & Venogram & $\begin{array}{l}\text { Fragmin } 1 / 16(6 \%) \\
\text { Control } 8 / 13(62 \%)\end{array}$ & Not specified \\
\hline $\begin{array}{l}\text { Nightingale et al (1997) } \\
\text { (cohort study) }\end{array}$ & 832 & External & $\begin{array}{l}\text { Sublavian+ } \\
\text { jugular+femoral }\end{array}$ & Warfarin I mg daily & $\begin{array}{l}\text { Mean } \\
122 \text { days }\end{array}$ & $\begin{array}{l}\text { Ultrasound } \pm \\
\text { venogram }\end{array}$ & Symptomatic only & Warfarin $42 / 949(4 \%)$ \\
\hline $\begin{array}{l}\text { Heaton et al }(2002)^{20} \\
\text { (open randomised study) }\end{array}$ & 88 & External & Subclavian & Warfarin I mg daily & 90 days & Venogram & $\begin{array}{l}\text { Warfarin 8/45 (18\%) } \\
\text { Control 5/43 (12\%) }\end{array}$ & Not specified \\
\hline $\begin{array}{l}\text { Mismetti et al }(2003)^{21} \\
\text { (open randomised study) }\end{array}$ & 59 & Port & $\begin{array}{l}\text { Subclavian+ } \\
\text { jugular }\end{array}$ & $\begin{array}{l}\text { Nadroparin } 2850 \mathrm{U} \\
\text { or warfarin } 1 \mathrm{mg}\end{array}$ & 90 days & Venogram & $\begin{array}{l}\text { Nadroparin } 6 / 21(29 \%) \\
\text { warfarin } 4 / 24(17 \%)\end{array}$ & $\begin{array}{l}\text { Nadroparin I/2I (5\%) } \\
\text { Warfarin 2/24 (8\%) }\end{array}$ \\
\hline $\begin{array}{l}\text { Couban et al }(2005)^{22} \\
\text { (placebo RCT) }\end{array}$ & 255 & $\begin{array}{l}\text { Port+ } \\
\text { External }\end{array}$ & $\begin{array}{l}\text { Sublavian+ } \\
\text { jugular }\end{array}$ & $\begin{array}{l}\text { Warfarin I mg } \\
\text { or placebo }\end{array}$ & $\begin{array}{l}\text { Catheter } \\
\text { duration }\end{array}$ & $\begin{array}{l}\text { Ultrasound } \pm \\
\text { venogram }\end{array}$ & Symptomatic only & $\begin{array}{l}\text { Warfarin 6/130(5\%) } \\
\text { Placebo 5/I25 (4\%) }\end{array}$ \\
\hline
\end{tabular}


of cases involving noncancer patients (Marie et al, 1998; Marinella et al, 2000). The actual incidence of CVC-related thromboses reported in cancer patients without thromboprophylaxis varies widely across different prospective studies (Table 1), and is highly dependent upon the nature of the study design. In particular, marked differences relate to whether clinical symptomatic thrombosis or asymptomatic thrombosis (detected only by venogram screening), are used as the endpoint of the study. It is also important to note that the incidence of both symptomatic (1$8 \%)$ and asymptomatic (12-18\%) CVC-associated VTE reported in more recent studies (Mismetti et al, 2003; Couban et al, 2005; Verso et al, 2005) is also significantly lower than that reported in the older studies (symptomatic VTE $0-25 \%$; asymptomatic VTE 27-62\%) (Bozzetti et al, 1983; Bern et al, 1990; Monreal et al, 1996). This important observation may reflect improvements in the biocompatibility of the CVCs, and/or improvements in CVC insertion techniques.

In the prospective studies included in this review, two studies investigated the risk of venous thrombosis specifically associated with the use of implantable ports in cancer patients not receiving thromboprophylaxis. In a prospective follow-up study of 40 cancer patients with Port-a-Cath subclavian venous catheters who did not receive any thromboprophylaxis, Bern et al (1990) observed 15 (37.5\%) venogram-proven DVT (10 of which were symptomatic) after 90 days. In this small study, the incidence of thrombosis was not influenced by either the age of the patient, or by the tumour type. In a similar study, Monreal et al (1996) identified catheterrelated VTE by venography in $8 / 13(62 \%)$ cancer patients with Port-a-Caths in the absence of prophylaxis.

Although several retrospective studies have suggested that the risk of thrombosis associated with external catheters may be significantly greater than that observed with implantable ports, this question has not been addressed in a prospective study. In terms of the different external catheters used in clinical oncology practise, the risk of thrombotic complications appears equivalent for both Hickman and Groshong catheters (Eastridge and Lefor, 1995). However, various other factors have been reported to influence the incidence of catheter-related thrombosis. For example, the risk of VTE is significantly higher in cancer patients who receive triple-lumen compared to double-lumen catheters and is higher if the catheter is inserted into the left rather than right subclavian vein (Gould et al, 1993; Craft et al, 1996). Furthermore, increased incidence of thrombosis has also been observed in cancer patients where the final catheter tip position has been placed above the T3 level (Eastridge and Lefor, 1995).

\section{Warfarin thromboprophylaxis in cancer patients with CVC}

In view of the high risk of VTE associated with using indwelling CVC in cancer patients, several reviews have advocated the use of primary thromboprophylaxis (Klerk et al, 2003). However, it is well established that the risks of bleeding are significantly higher in cancer patients (Krauth et al, 1987; Bona et al, 1997). The risk of major bleeding associated with warfarin therapy can be reduced, by lowering the target INR. Studies have also shown that even low-dose warfarin $\left(1 \mathrm{mg} \mathrm{day}^{-1}\right)$ can reduce the rate of thrombin generation in vivo, (Bauer and Rosenberg, 1987) and significantly reduce the incidence of DVT following gynaecologic surgery (Poller et al, 1987). Furthermore, in patients with stage IV breast cancer, minidose warfarin (adjusted to maintain a target INR $1.3-$ 1.9), was effective in reducing lower limb DVT (Levine et al, 1994). On the basis of these observations, several groups have studied the efficacy of minidose warfarin in cancer patients with CVC.

In an open randomised trial, Bern et al (1990) enrolled 82 cancer patients who required central venous access (Port-a-Cath subclavian catheters). The patients were then randomised to receive, or not to receive, warfarin ( $1 \mathrm{mg}$ daily), beginning 3 days before $\mathrm{CVC}$ insertion and continuing for a further 90 days. Prothrombin times (PT) were monitored regularly throughout the study, and all patients were subsequently screened by venogram. Of the 42 patients randomised to receive low-dose warfarin therapy, four (9.5\%) patients developed DVT. Conversely, in the control group of patients not receiving warfarin, 15 out of $40(37.5 \%)$ patients were found to have developed venogram-proven DVT during the 90 -day follow-up period $(P<0.001)$. Despite this marked therapeutic efficacy, the use of low-dose warfarin did not significantly influence the PT in the majority of the patients studied, and was not associated with any increase in bleeding.

Minidose warfarin thromboprophylaxis has also been used as thrombophylaxis to prevent CVC-related thrombosis in patients with haematological malignancies. Boraks et al (1998) prospectively treated 108 consecutive patients with warfarin $1 \mathrm{mg}^{-1 a y}{ }^{-1}$ commenced on the day of line insertion, and then continued until the catheter was removed. The prothrombin time was measured three times per week, and the warfarin dose adjusted to maintain a target INR <1.6. All patients presenting with clinical signs suggestive of DVT were investigated with Doppler ultrasound and/or venogram. Of the patients receiving warfarin prophylaxis, $5 \%$ developed clinically symptomatic DVT. The use of minidose warfarin was not associated with any increased bleeding complications. However, four patients were noted to have prolonged PT ( $>20 \mathrm{~s}$ ) that necessitated temporary cessation of their warfarin therapy. Unfortunately this study did not include a prospective control cohort. Rather the effect of minidose warfarin was compared to a historical control group, which fails to satisfy the selection criteria of this systematic review.

Although the study of Bern et al demonstrated significant efficacy for minidose warfarin thromboprophylaxis in cancer patients, more recent studies have failed to reproduce these findings. Heaton et al (2002) investigated 88 adult patients with haematological malignancies who required insertion of either a double lumen Hickman line $(n=78)$ or double lumen Groshong catheter $(n=10)$. A total of 45 patients were randomised to receive warfarin $1 \mathrm{mg}$ daily started on the day of insertion and continued for a further 90 days or until development of clinical thrombosis. The INR was monitored on a weekly basis, and if greater than 1.5, warfarin therapy was temporarily discontinued. In patients with clinical findings suggestive of either catheter thrombosis (difficulty in aspirating or injecting into the line), or DVT (arm pain or swelling), a venogram was performed. There were eight $(18 \%)$ cases of confirmed thrombosis in the warfarin-treated group (six patients with catheter-related thrombosis and two patients with DVT), as opposed to five (12\%) cases in the control group (four patients with catheter-related thrombosis and one patient with DVT), leading the authors to conclude that minidose warfarin was of no therapeutic benefit in preventing CVC-related thrombosis in patients with haematological malignancies. However, despite the original study design, it is noteworthy that the patients randomised to the warfarin treatment arm of this study only received warfarin therapy for a median 41 days. This reduced warfarin compliance related to a variety of factors including elevated INR, severe thrombocytopenia, and bleeding complications in one case. In all, 10 patients treated with warfarin developed prolonged INR $>1.5$, compared to five patients with no warfarin treatment. One patient on warfarin and INR $>1.5$ developed haematuria. However, this patient had Non-Hodgkin's lymphoma with tumour involving his ureters, and was also uraemic.

More recently, a larger randomised, double-blind, placebocontrolled trial of 255 patients with solid tumours and haematological malignancies also failed to demonstrate any reduction in the incidence of symptomatic venous thrombosis for patients treated with minidose warfarin. Couban et al (2005) randomised patients to receive either warfarin $1 \mathrm{mg}$ daily or placebo. Therapy was commenced within $72 \mathrm{~h}$ of CVC insertion, and continued until the catheter was removed. Ultrasound and venography were only performed in patients presenting with symptoms suggestive of 
venous thrombosis. In total, there were 11 symptomatic CVCrelated thrombotic events - five (4\%) in the placebo group and six (4\%) in the warfarin arm, respectively. The explanation for the conflicting conclusions reached by these studies may well relate to important differences in study design (most notably for example, Bern et al performed routine screening venography). In addition, although Bern's cohort consisted mainly of patients with solid tumours and lymphomas, the cohort enrolled in the study of Couban predominantly suffered from haematological malignancies.

\section{LMWH thromboprophylaxis in cancer patients with CVC}

Warfarin therapy in cancer patients is associated with a number of important clinical issues. In particular, fluctuations in INR on equivalent doses of warfarin are a common problem due to GI disturbances (vomiting, diarrhoea), cachexia, liver disease and chemotherapy. In addition, warfarin therapy has a delayed onset of action, with the full anticoagulant effect not being reached until 2-3 days following commencement of treatment. This delayed onset of anticoagulant effect, together with the long half-life of warfarin, means that any surgical interventions must be carefully planned in cancer patients maintained on warfarin.

In view of the problems associated with use of warfarin in oncology patients, recent studies have investigated the role of LMWH thromboprophylaxis in cancer patients with CVC. In an open, prospective study, Monreal et al (1996) studied 29 cancer patients who were having Port-a-Caths inserted. In all, 16 patients were randomised to receive LMWH (Dalteparin 2500IU s.c. once daily, starting $2 \mathrm{~h}$ prior to insertion of CVC and continuing for 90 days). Venography was performed after 90 days or sooner if VTE symptoms were observed. The study was terminated early on the recommendation of the institutional review committee, as DVT developed in only $6 \%$ of the LMWH treatment group as opposed to $62 \%$ of the controls group $(P=0.002)$. The use of LMWH was not associated with any increase in bleeding.

More recently, Verso et al reported the first randomised, double-blind, placebo-controlled study, to assess the efficacy and safety of enoxaparin thromboprophylaxis (Verso et al, 2005). A total of 385 cancer patients (including those with haematological malignancy) were randomised to either enoxaparin $(40 \mathrm{mg}$ subcutaneously once daily) or placebo, commencing $2 \mathrm{~h}$ before $\mathrm{CVC}$ insertion and continued for 6 weeks. All patients underwent screening venography performed 6 weeks after randomisation, which demonstrated venous thrombosis in 22 cancer patients (14\%) treated with enoxaparin, compared to 28 cases $18 \%$ ) treated with placebo, respectively. The authors concluded that LMWH thromboprophylaxis with enoxaparin was not associated with any significant reduction in CVC-associated venous thrombosis. In keeping with other recently reported studies, it is important to note that the rate of asymptomatic CVC-associated thrombosis in the placebo arm of this trial (18\%) was significantly lower than that reported in the older studies (38 and 62\%) (Bern et al, 1990; Monreal et al, 1996) In view of this reduction in absolute baseline thrombotic complications, future studies will need to be more highly powered in order to detect subtle differences with introduction of thromboprophylaxis.

The relative efficacies of LMWH compared to minidose warfarin have been compared in only one study. Mismetti et al (2003) randomised 59 cancer patients to receive either minidose warfarin $\left(1 \mathrm{mg} \mathrm{day}^{-1}\right)$ or LMWH (nadroparin 2850IU OD). Over the course of a 90-day follow-up, the incidence of venogram-proven upper extremity DVT was $17 \%$ in the warfarin-treated group compared to $29 \%$ for the nadroparin group $(P=0.48)$. In this study, one patient with lung cancer receiving nadroparin developed fatal haemoptysis. On the basis of this small pilot, the authors concluded that there was no significant difference in efficacy between minidose warfarin and LMWH thromboprophylaxis.

\section{DISCUSSION}

Patients with cancer are at increased risk of VTE, and placement of CVC further increases this risk. The development of upper extremity venous thrombosis in a cancer patient with an indwelling CVC constitutes an important clinical complication. Pulmonary embolism is generally reported to occur in $10-20 \%$ of patients with upper limb DVT (Horattas et al, 1988; Horne et al, 1995). However, in cancer patients with CVC-related thrombosis, the risk of $\mathrm{PE}$ is significantly higher, occurring in $15 \%$ of cases even if managed using therapeutic anticoagulation (Monreal et al, 1994). Consequently, the development of objectively proven upper limb venous thrombosis usually necessitates CVC removal. Subsequently another CVC will need to be inserted at another site. However, even the temporary loss of central venous access can result in significant clinical problems. Furthermore, following the objective diagnosis of any catheter-related DVT, cancer patients will require full-dose therapeutic anticoagulation (with heparin and/or warfarin) with the attendant risks of bleeding. Previous studies have also suggested an increased incidence of CVC sepsis in patients who develop CVC-related thrombosis (Klerk et al, 2003). In the longer term, post-thrombotic syndrome has been reported in $30 \%$ of cancer patients following upper limb DVT, and permanent venous damage can result from CVCs (approximately $30 \%$ cases), even in cancer patients without a history of CVCrelated thrombosis (Kerr et al, 1990).

In this context, the question of whether primary thromboprophylaxis should be considered for cancer patients with CVC is clearly of direct clinical importance. However, as we have demonstrated in this systematic review, there is a paucity of evidence upon which to base clinical decision making regarding the role of thromboprophylaxis. In total, only nine prospective studies investigating the role of thromboprophylaxis in adult patients with cancer have been identified, and only within the last year have the first double-blind, randomised-controlled studies been published. Moreover, six of these nine studies enrolled fewer than 125 cancer patients in total (Bozzetti et al, 1983; Bern et al, 1990; Monreal et al, 1996; Boraks et al, 1998; Heaton et al, 2002; Mismetti et al, 2003). In view of the small numbers of patients in these studies, it is not perhaps surprising that they reached conflicting conclusions. Furthermore, as a consequence of the lack of patient numbers, stratification for important confounding factors (e.g. antithrombin deficiency; elevated homocysteine levels; side of CVC placement) has not been possible. In addition, the patient cohorts enrolled in the different studies demonstrate marked differences. For example, they include a wide variety of different tumour types and stages. Moreover, in only some of the studies were patients with haematological malignancies included, together with patients with solid tumours. Clearly, larger randomised studies are required in order to establish both the efficacy and the safety of thromboprophylaxis in cancer patients with CVCs.

The problem of small cohort size, and discrepant populations of patients, makes it difficult to perform any meaningful comparisons between studies in the form of conventional meta-analysis, or even systematic review. This is compounded by the fact there are critical differences in study design. For example, the wide range in the incidence of thrombotic events reported is highly influenced by whether the end point of the study was defined as symptomatic or asymptomatic thrombosis. In addition, some of the studies failed to make any distinction between DVT, and thrombosis restricted to the lumen of the catheter. Finally, interpretation of the data is further complicated by the fact that a significant minority of patients enrolled in these studies were unable to complete their assigned period of thromboprophylaxis. For example, in the study of Heaton et al (2002), 38\% of lines had to be removed before 90 days in patients receiving warfarin due to line infection, and other causes besides thrombosis. 
Notwithstanding the limitations discussed above, several conclusions can be drawn from this systematic review of the literature. Firstly, as previously discussed, the rate of CVC-related venous thrombosis is significantly lower in recent compared to older studies. In particular, symptomatic upper extremity DVT is now relatively unusual, occurring in only approximately $5 \%$ of cancer patients. In contrast, asymptomatic VTE is still detectable in around $20 \%$ cases. The clinical significance of such asymptomatic thrombi in patients with cancer remains unclear, as little is known regarding the natural history of CVC-related DVT. Further studies addressing this issue would be of clinical value.

Secondly, on the basis of the available data, it is not possible to recommend using routine thromboprophylaxis for all cancer patients receiving CVCs. In particular, it is important to note that the only two placebo-controlled trials performed to date failed to demonstrate any beneficial effect for either warfarin or LMWH (enoxaparin) thromboprophylaxis (Couban et al, 2005; Verso et al, 2005). However, it remains unclear how therapeutic efficacy and safety might vary over a range of different warfarin or LMWH doses. For example, dose of LMWH has been shown to be of critical importance in determining efficacy in cancer patients undergoing abdominal surgery (Carr and Rabinowitz, 2000). In addition, the future use of LMWH thromboprophylaxis may be influenced by accumulating recent literature suggesting that use of LMWH in cancer patients is associated with improved survival (Altinbas et al, 2004; Kakkar et al, 2004; Klerk et al, 2005; Lee et al, 2005). This survival benefit is not entirely explained by a reduction in symptomatic VTE, raising the intriguing possibility that LMWH may also exert a direct effect on tumour cell biology.

\section{REFERENCES}

Altinbas M, Coskun HS, Er O, Ozkan M, Eser B, Unal A, Cetin M, Soyuer S (2004) A randomized clinical trial of combination chemotherapy with and without low-molecular-weight heparin in small cell lung cancer. J Thromb Haemost 2: 1266-1271

Ambrus JL, Ambrus CM, Mink IB, Pickren JW (1975) Causes of death in cancer patients. $J$ Med 6: $61-64$

Baglin TP, Boughton BJ (1986) Central venous thrombosis due to bolus injections of antileukaemic chemotherapy. Br J Haematol 63: 606-607

Bauer KA, Rosenberg RD (1987) The pathophysiology of the prethrombotic state in humans: insights gained from studies using markers of hemostatic system activation. Blood 70: $343-350$

Bern MM, Lokich JJ, Wallach SR, Bothe Jr A, Benotti PN, Arkin CF, Greco FA, Huberman M, Moore C (1990) Very low doses of warfarin can prevent thrombosis in central venous catheters. A randomized prospective trial. Ann Intern Med 112: $423-428$

Bick RL (1978) Alterations of hemostasis associated with malignancy: etiology, pathophysiology, diagnosis and management. Semin Thromb Hemost 5: $1-26$

Bona RD, Hickey AD, Wallace DM (1997) Efficacy and safety of oral anticoagulation in patients with cancer. Thromb Haemost 78: 137-140

Boraks P, Seale J, Price J, Bass G, Ethell M, Keeling D, Mahendra P, Baglin T, Marcus R (1998) Prevention of central venous catheter associated thrombosis using minidose warfarin in patients with haematological malignancies. Br J Haematol 101: 483-486

Bozzetti F, Scarpa D, Terno G, Scotti A, Ammatuna M, Bonalumi MG, Ceglia E (1983) Subclavian venous thrombosis due to indwelling catheters: a prospective study on 52 patients. JPEN J Parenter Enteral Nutr 7: $560-562$

Broviac JW, Cole JJ, Scribner BH (1973) A silicone rubber atrial catheter for prolonged parenteral alimentation. Surg Gynecol Obstet 136: 602-606

Carr KM, Rabinowitz I (2000) Physician compliance with warfarin prophylaxis for central venous catheters in patients with solid tumors. J Clin Oncol 18: $3665-3667$

Cortelezzi A, Moia M, Falanga A, Pogliani EM, Agnelli G, Bonizzoni E, Gussoni G, Barbui T, Mannucci PM (2005) Incidence of thrombotic complications in patients with haematological malignancies with central
Finally, from the studies included in this review, it is clear that thromboprophylaxis with either warfarin or LMWH is generally well tolerated in cancer patients with indwelling CVC. Indeed thromboprophylaxis appears to be safe, even in patients with haematological malignancies who often have concurrent severe thrombocytopenia (Boraks et al, 1998; Cortelezzi et al, 2005). However, it is important to recognise that minidose warfarin $\left(1 \mathrm{mg} \mathrm{day}^{-1}\right)$ can have a significant effect on the prothrombin time in cancer patients (Heaton et al, 2002; Masci et al, 2003; Mismetti et al, 2003; Magagnoli et al, 2005). The aetiology of this increased prothrombin time is multifactorial, and includes anorexia and liver metastases (Magagnoli et al, 2005). In addition, it is well recognised that warfarin can interact with other medications, leading to significant increases in INR levels. In particular, several studies have demonstrated an adverse reaction between warfarin and fluorouracil (FU) (Masci et al, 2003; Magagnoli et al, 2005). Masci et al (2003) observed significant elevation of the INR in 33\% of patients receiving the combination of minidose warfarin and FU. Similarly, Magagnoli et al (2005) demonstrated that concomitant use of minidose warfarin and the FOLFOX regimen (FU, folinic acid and oxaliplatin) resulted in INR elevation in $40 \%$ patients (range 1.5-9.4; median 2.9). Consequently, it is evident that minidose warfarin can significantly prolong the prothrombin time, at least in selected subgroups of cancer patients. On this basis, it would appear prudent that all cancer patients treated with minidose warfarin should have routine prothrombin time (INR) monitoring, and have their dose of warfarin titrated to maintain an INR $\leqslant 1.5$. To date there is no evidence to suggest that anti-Xa monitoring is indicated for cancer patients receiving prophylactic dose LMWH thromboprophylaxis. venous catheters: a prospective multicentre study. $\mathrm{Br}$ J Haematol 129: $811-817$

Couban S, Goodyear M, Burnell M, Dolan S, Wasi P, Barnes D, Macleod D, Burton E, Andreou P, Anderson DR (2005) Randomized placebocontrolled study of low-dose warfarin for the prevention of central venous catheter-associated thrombosis in patients with cancer. J Clin Oncol 23: $4063-4069$

Craft PS, May J, Dorigo A, Hoy C, Plant A (1996) Hickman catheters: leftsided insertion, male gender, and obesity are associated with an increased risk of complications. Aust NZ J Med 26: 33-39

De Cicco CM, Matovic M, Balestreri L, De AV, Fracasso A, Morassut S, Coran F, Babare R, Buonadonna A, Testa V (1995) Antithrombin III deficiency as a risk factor for catheter-related central vein thrombosis in cancer patients. Thromb Res 78: $127-137$

Eastridge BJ, Lefor AT (1995) Complications of indwelling venous access devices in cancer patients. J Clin Oncol 13: 233-238

Geerts WH, Pineo GF, Heit JA, Bergqvist D, Lassen MR, Colwell CW, Ray JG (2004) Prevention of venous thromboembolism: the Seventh ACCP Conference on Antithrombotic and Thrombolytic Therapy. Chest 126: $338 \mathrm{~S}-400 \mathrm{~S}$

Gould JR, Carloss HW, Skinner WL (1993) Groshong catheter-associated subclavian venous thrombosis. Am J Med 95: 419-423

Heaton DC, Han DY, Inder A (2002) Minidose (1 mg) warfarin as prophylaxis for central vein catheter thrombosis. Intern Med J 32: $84-88$

Heit JA, Silverstein MD, Mohr DN, Petterson TM, O’Fallon WM, Melton III LJ (2000) Risk factors for deep vein thrombosis and pulmonary embolism: a population-based case-control study. Arch Intern Med 160: $809-815$

Hickman RO, Buckner CD, Clift RA, Sanders JE, Stewart P, Thomas ED (1979) A modified right atrial catheter for access to the venous system in marrow transplant recipients. Surg Gynecol Obstet 148: $871-875$

Horattas MC, Wright DJ, Fenton AH, Evans DM, Oddi MA, Kamienski RW, Shields EF (1988) Changing concepts of deep venous thrombosis of the upper extremity - report of a series and review of the literature. Surgery 104: $561-567$ 
Horne III MK, May DJ, Alexander HR, Steinhaus EP, Whitman ED, Chang RC, Doppman JL (1995) Venographic surveillance of tunneled venous access devices in adult oncology patients. Ann Surg Oncol 2: $174-178$

Kakkar AK, Levine MN, Kadziola Z, Lemoine NR, Low V, Patel HK, Rustin G, Thomas M, Quigley M, Williamson RC (2004) Low molecular weight heparin, therapy with dalteparin, and survival in advanced cancer: the fragmin advanced malignancy outcome study (FAMOUS). J Clin Oncol 22: $1944-1948$

Kearon C (2003) Natural history of venous thromboembolism. Circulation 107: I22 - I30

Kerr TM, Lutter KS, Moeller DM, Hasselfeld KA, Roedersheimer LR, McKenna PJ, Winkler JL, Spirtoff K, Sampson MG, Cranley JJ (1990) Upper extremity venous thrombosis diagnosed by duplex scanning. Am J Surg 160: 202-206

Klerk CP, Smorenburg SM, Buller HR (2003) Thrombosis prophylaxis in patient populations with a central venous catheter: a systematic review. Arch Intern Med 163: 1913-1921

Klerk CP, Smorenburg SM, Otten HM, Lensing AW, Prins MH, Piovella F, Prandoni P, Bos MM, Richel DJ, van TG, Buller HR (2005) The effect of low molecular weight heparin on survival in patients with advanced malignancy. J Clin Oncol 23: 2130-2135

Krauth D, Holden A, Knapic N, Liepman M, Ansell J (1987) Safety and efficacy of long-term oral anticoagulation in cancer patients. Cancer 59: 983-985

Lee AY (2005) Management of thrombosis in cancer: primary prevention and secondary prophylaxis. Br J Haematol 128: 291-302

Lee AY, Rickles FR, Julian JA, Gent M, Baker RI, Bowden C, Kakkar AK, Prins M, Levine MN (2005) Randomized comparison of low molecular weight heparin and coumarin derivatives on the survival of patients with cancer and venous thromboembolism. J Clin Oncol 23: 2123-2129

Levine M, Hirsh J, Gent M, Arnold A, Warr D, Falanga A, Samosh M, Bramwell V, Pritchard KI, Stewart D (1994) Double-blind randomised trial of a very-low-dose warfarin for prevention of thromboembolism in stage IV breast cancer. Lancet 343: 886-889

Magagnoli M, Masci G, Castagna L, Bramanti S, Morenghi E, Carnaghi C, Santoro A (2005) High incidence of haemostatic interference in cancer patients treated with FOLFOX regimen and concomitant minidose of warfarin. Br I Haematol 129: 709-710

Marie I, Levesque H, Cailleux N, Primard E, Peillon C, Watelet J, Courtois H (1998) Deep venous thrombosis of the upper limbs. Apropos of 49 cases. Rev Med Intern 19: 399-408
Marinella MA, Kathula SK, Markert RJ (2000) Spectrum of upper-extremity deep venous thrombosis in a community teaching hospital. Heart Lung 29: $113-117$

Masci G, Magagnoli M, Zucali PA, Castagna L, Carnaghi C, Sarina B, Pedicini V, Fallini M, Santoro A (2003) Minidose warfarin prophylaxis for catheterassociated thrombosis in cancer patients: can it be safely associated with fluorouracil-based chemotherapy? J Clin Oncol 21: 736-739

Mismetti P, Mille D, Laporte S, Charlet V, Buchmuller-Cordier A, Jacquin JP, Fournel P, Dutrey-Dupagne C, Decousus H (2003) Low-molecularweight heparin (nadroparin) and very low doses of warfarin in the prevention of upper extremity thrombosis in cancer patients with indwelling long-term central venous catheters: a pilot randomized trial. Haematologica 88: $67-73$

Monreal M, Alastrue A, Rull M, Mira X, Muxart J, Rosell R, Abad A (1996) Upper extremity deep venous thrombosis in cancer patients with venous access devices - prophylaxis with a low molecular weight heparin (Fragmin). Thromb Haemost 75: 251-253

Monreal M, Raventos A, Lerma R, Ruiz J, Lafoz E, Alastrue A, Llamazares JF (1994) Pulmonary embolism in patients with upper extremity DVT associated to venous central lines - a prospective study. Thromb Haemost 72: $548-550$

Nightingale CE, Norman A, Cunningham D, Young J, Webb A, Filshie J (1997) A prospective analysis of 949 long-term central venous access catheters for ambulatory chemotherapy in patients with gastrointestinal malignancy. Eur J Cancer 33: 398-403

Oger E (2000) Incidence of venous thromboembolism: a community-based study in Western France. EPI-GETBP Study Group. Groupe d'Etude de la Thrombose de Bretagne Occidentale. Thromb Haemost 83: 657-660

Piccioli A, Prandoni P, Ewenstein BM, Goldhaber SZ (1996) Cancer and venous thromboembolism. Am Heart J 132: 850-855

Poller L, McKernan A, Thomson JM, Elstein M, Hirsch PJ, Jones JB (1987) Fixed minidose warfarin: a new approach to prophylaxis against venous thrombosis after major surgery. Br Med J (Clin Res Ed) 295: 1309-1312

Tesselaar ME, Ouwerkerk J, Nooy MA, Rosendaal FR, Osanto S (2004) Risk factors for catheter-related thrombosis in cancer patients. Eur J Cancer 40: $2253-2259$

Verso M, Agnelli G, Bertoglio S, Di Somma FC, Paoletti F, Ageno W, Bazzan M, Parise P, Quintavalla R, Naglieri E, Santoro A, Imberti D, Soraru M, Mosca S (2005) Enoxaparin for the prevention of venous thromboembolism associated with central vein catheter: a double-blind, placebocontrolled, randomized study in cancer patients. J Clin Oncol 23: 4057-4062 